\title{
Cantos amebeos: de Garcilaso a Góngora
} Amoebean Songs, from Garcilaso to Góngora

\author{
Jesús Gómez \\ Universidad Autónoma de Madrid \\ jesus.gomez@uam.es \\ ORCID iD: http://orcid.org/0000-0001-8965-1659
}

\section{RESUMEN}

Este artículo analiza las principales líneas en la evolución del canto amebeo en la poesía pastoril española de los siglos XVI y XVII, después de su aclimatación en la égloga tercera de Garcilaso de la Vega hasta su trayectoria posterior, casi siempre asociada a la figura del pastor-poeta. Como procedimiento formal derivado de la égloga, el canto amebeo no adquiere independencia completa, pero posee sus propias convenciones literarias con respecto a otras variedades de la poesía dialogada.

Palabras Clave: poesía dialogada; canto amebeo; égloga; Garcilaso de la Vega.

\begin{abstract}
This article analyses the main evolutionary lines of Amoebean song in XVI and XVII century Spanish pastoral poetry after Garcilaso de la Vega's Third eclogue, and focuses on its ulterior life, often linked to the figure of the shepherd-poet. As a formal element derived from the eclogue, the Amoebean song did not become completely independent; it nevertheless did show specific literary features in relation to other varieties of poetry in dialogue-form.
\end{abstract}

Key words: Poetry in dialogue-form; Amoebean song; Eclogue; Garcilaso de la Vega.

En relación a la historia de la poesía española de los siglos XVI y XVII, apenas hay bibliografía específica sobre el canto amebeo a pesar de la creciente importancia de los estudios dedicados a la tradición pastoril derivada, aunque no en exclusiva, de Virgilio, quien con sus diez églogas o bucólicas fijó para la posteridad los rasgos principales del modelo genérico ${ }^{1}$. De hecho, uno de los

${ }^{1}$ Como han estudiado, además de V. Cristóbal (1980), Bayo (1970), Blecua (2006) y González Vázquez (1991). Las consideraciones siguientes, que se inscriben en los proyectos 
escasos trabajos dedicados a la proyección del canto amebeo se centra en la égloga VII de Virgilio que, según Carmen Escudero (1982: 4): «introduce una novedad en el canto alternante creado por Teócrito; los dos pastores que compiten en esta égloga no cantan el mismo tema, como ocurría en el idilio y, además, lo que cantan podría simbolizarse en el haz y el envés de una misma hoja, ya que son temas a la vez unidos y opuestos». El procedimiento, por tanto, se asocia estrechamente a la tradición poética de la égloga, sobre todo después del Renacimiento cuando «el canto amebeo no encuentra obstáculos para mantenerse en la recuperada poesía pastoril» (Mateo 1991: 753).

Por otra parte, en la tradición más amplia de la contienda poética, el amebeo se diferencia de otras variantes de la poesía polémica a las que se refiere Guillén (1985: 159-162) como el conflictus o debate poético medieval, la tensó y el joc partit de los trovadores provenzales, ya que de acuerdo con su etimología (gr. amoibaios, 'alterno') se define por la alternancia en el canto de los dos pastores-poetas, el segundo de los cuales está obligado a responder utilizando el mismo esquema, métrico y sintáctico, del primero. Otra condición sine qua non es que exista una correspondencia temática entre el contenido de los sucesivos pares de estrofas, como ocurre en el amebeo que los pastores Tirreno y Alcino introducen al final de la égloga tercera de Garcilaso, según el preciso comentario de El Brocense cuando señala su procedencia virgiliana:

Aquí comienza un género de Bucólica, que llaman los griegos canto Amebeo, que es responsivo, en el cual se suele guardar esta ley: que el que comienza es libre, y puede mudar propósitos, mas el que responde y sigue, o ha de decir mucho más en la misma materia, o lo contrario, y ansí se hace aquí, imitando el proceder de Virgilio en la tercera y séptima Égloga (Gallego Morell 1972: 302).

Herrera sigue claramente a El Brocense cuando afirma de manera más resumida: «La ley de este verso [amebeo] es decir cosas mayores o contrarias que el primero, y así es más difícil la parte que responde» (Gallego Morell 1972: 584-585), si bien el modelo común de ambos se remonta a la definición que ofrece Servio: «amoebaeum autem est quotiens qui canunt et aequali numero uersuum utuntur et ita se habet responsio ut aut maius aut contrarium aliquid dicant» (Virgilio 2000: 113) .

de investigación HAR 2015-68946-C3-1-P del Ministerio de Economía y Competitividad y H2015/HUM-3415 de la Comunidad de Madrid/Unión Europea (Fondo Social Europeo), adscritos al Instituto Universitario La Corte en Europa (IULCE), se relacionan con la proyección de las églogas garcilasianas acorde con el «orden clásico» que, como explica Ynduráin (2000: 17-45), surge del principio de imitatio cuya concepción supone que cualquier arte posee unas determinadas reglas o convenciones susceptibles de ser expuestas y aprendidas.

2 Como afirma Schnabel (1996: 27): «En Garcilaso comienza la tradición de la égloga clásica en España y, a su vez, con los escolios de Herrera a la obra del toledano se inaugu- 
Una vez definido el modelo virgiliano, veremos las principales líneas en su evolución a partir de la égloga tercera de Garcilaso, ya que el canto amebeo está puesto por lo general en boca del idealizado pastor-poeta, de acuerdo con las convenciones de la tradición bucólica ${ }^{3}$. Para ello, se analiza una serie de cantos amebeos que prolongan la influencia de la mencionada égloga tercera, con un propósito selectivo para diferenciar una variante menos clasicista, que aparece en La Diana de Montemayor a mediados del siglo XVI, del modelo virgiliano del canto alterno adaptado por el poeta toledano y que Francisco de la Torre imita en su égloga «Dafnis».

Con el amebeo de la égloga tercera, ha sido necesario comparar el contraste dialogado entre los dos pastores de la primera, Salicio y Nemoroso, derivado de la égloga VIII de Virgilio. Aunque no responde a la definición del carmen amoebaeum establecida por Servio y recordada desde los primeros comentaristas de Garcilaso, veremos que la crítica ha confundido los respectivos cantos de Salicio y Nemoroso con la contienda poética del original virgiliano. Por tanto, la hipótesis de trabajo queda establecida a partir de la investigación sobre ambas églogas garcilasianas, teniendo en cuenta que la poética del canto alterno determina que el poeta-pastor que interviene en segundo lugar, además del mismo esquema métrico y sintáctico, debe cantar lo contrario («aut contrarium») o sobrepujarlo («aut maius») de tal modo que se establece una estricta alternancia temática entre los sucesivos pares de versos y estrofas.

\section{A PARTIR DE GARCILASO}

Dentro del amplio y variado estado de la cuestión sobre la poesía áurea (Núñez Rivera y Rico García 2005; actualizado por Osuna y Sánchez Jiménez 2012), dada la escasez de bibliografía específica sobre el canto amebeo, vamos a referirnos tan sólo a las principales ediciones y estudios más signifi-

ra la poética española de lo pastoril». No resulta difícil documentar, a partir de los comentaristas de Garcilaso, definiciones semejantes del amebeo en otros tratadistas de la época, como Cascales (1975: 291), quien en sus Tablas poéticas (1617) afirma: «Hay también en las Bucólicas unos versos que llaman Amebeos con esta ley y obligación, que quando van cantando dos pastores a competencia, el que segunda ha de decir mayor concepto que el primero, o contrario concepto».

${ }^{3}$ Aunque Schnabel (1996) afirma que la crítica ha mostrado escaso interés por la poesía pastoril, no menciona la interesante tesis de Ramón Mateo Mateo (1991). Además del artículo de Aurora Egido (1985) y de la restante bibliografía citada por Gómez (1991-1992 y 1993), cabe añadir Pérez-Abadín (2004) y Fosalba (2004), quien se refiere a «la epidemia del bucolismo» (García López, Fosalba y Pontón 2013: 427-443), junto con el fundamental volumen colectivo coordinado por Begoña López Bueno La égloga (2002), así como otros volúmenes del grupo de investigación dirigido por la misma coordinadora (López Bueno 2005), dentro de la teoría lírica de la época (Vega y Esteve 2004). 
cativos para el enfoque adoptado sobre la serie de amebeos que se analiza a continuación, comenzando por el de la égloga tercera de Garcilaso que protagonizan al final de la misma los pastores Tirreno y Alcino. Después de la dedicatoria (vv. 1-56), el narrador describe el escenario bucólico del Tajo donde aparecen las cuatro ninfas tejiendo cada una de ellas un tapiz (vv. 57228).

Precisamente la bucólica descripción de la escena se ve interrumpida cuando las ninfas oyen «al son de la zampoña (...)/ dos pastores a veces que cantaban» (vv. 287-288), donde la expresión «a veces» se refiere a sus dos cantos alternantes o por turno que se suceden uno a otro, como es propio del amebeo. En cada uno de los cuatro pares de octavas que lo constituyen (vv. 305-368), el intercambio de pregunta-respuesta o de afirmación-negación no se gobierna por las reglas pragmáticas habituales en la conversación, ya que el pastor que canta en segundo lugar (Tirreno) no confirma ni tampoco refuta el contenido del primero (Alcino), sino que establece un contraste estético cuya alternancia se inspira en el modelo de la virgiliana égloga VII, del que toma también la introducción en la que subraya la igualdad entre ambos pastores: «mancebos de una edad, d'una manera/ a cantar juntamente aparejados/ y a responder» (vv. 301-302) . $^{4}$

El primero de los cuatro pares de octavas está dedicado a las respectivas amadas: Tirreno-Flérida y Alcino-Filis, manteniendo la misma estructura sintáctica que comienza, en ambas octavas, por un vocativo, lo que viene a subrayar el carácter interactivo de la expresión amorosa del pastor, bien que in absentia, pues existe un contexto dialógico en el que físicamente sólo están presentes los dos pastores. Después del vocativo, aunque las respectivas construcciones sintácticas de la octava no sean idénticas del todo, en ambas aparece una oración condicional, en boca de Tirreno: «Flérida (...)/ Si tú respondes pura y amorosa/ al verdadero amor de tu Tirreno,/ a mi majada arribarás»...; y de Alcino: «Hermosa Filis (...)/ y de ti despojado yo me vea/ [...] si más que yo el murciélago desea/ la escuridad [...]/ por ver yo el fin [...]/ deste día» (vv. 305-320).

La identidad temática y sintáctica del primer par refuerza, además, la relación de contraste entre ambas interlocuciones, pues mientras la octava de Tirreno gira en torno al adjetivo «dulce» (v. 305), Alcino utiliza el de «amargo» (v. 314). Hay otra oposición secundaria entre la blancura de la amada de Tirre-

${ }^{4}$ Virgilio: «ambo florentes aetatibus, Arcades ambo,/ et cantare pares et respondere parati (...)/ Alternis igitur contendere uersibus ambo/ coepere» (VII, 4-5 y 18). En las notas a su edición (1995: 239), B. Morros señala que el pasaje le llega a Garcilaso probablemente a través de Sannazaro: «... ambiduo di Arcadia et egualmente a cantare et a rispondere apparecchiati» (Arcadia IV, 17-18). El nuevo ideal estilístico del escritor napolitano, quien incluye en su Arcadia tres cantos amebeos con que finalizan las «prosas» segunda, cuarta y novena, resulta básico para la recuperación del bucolismo virgiliano. 
no: «más blanca que la leche» (v. 307) y la «escuridad» (v. 318) a la que apela Alcino. Obsérvese que esta relación de contraste o de alteridad (dulce-amargo, blanca-escuridad) no implica contradicción lógica alguna entre las respectivas afirmaciones de los dos pastores, sino tan sólo un contraste estético asociado a la competición poética.

Garcilaso mantiene este mismo tipo de contraste en los restantes pares de su amebeo. En el segundo, si la llegada de Flérida viene acompañada del resurgir de la «dulce primavera» (v. 322) que hace reverdecer la alegría del pastor, la «furia» (v. 335) de Filis se compara con los efectos destructores que la tormenta causa tanto en la sierra como en la mar. En el par tercero, si Tirreno hace depender la fertilidad de la naturaleza de la mirada de su amada: «todo se convertirá en abrojos/ si dello aparta Flérida sus ojos» (vv. 343-344), Alcino explora la misma imagen en sentido opuesto: «pero si Filis por aquí tornare,/ hará reverdecer cuanto mirare» (vv. 351-352). En el cuarto y último par, la relación de contraste cambia, puesto que Alcino ya no dice exactamente lo contrario que Tirreno, sino que utiliza la otra posibilidad del amebeo: «cosas mayores», cuando ambos ponderan la excelencia de los árboles preferidos por sus amadas, en una estructura correlativa: los sauces que, según Tirreno sobrepujan al álamo, laurel y mirto; mientras que, según Alcino, la belleza de Filis sobrepuja al fresno y haya 5 .

Además de comprender el modelo de amebeo utilizado por Garcilaso en su égloga tercera compuesta en 1536, es importante compararlo con el de la primera compuesto por dos monólogos sucesivos en boca de Salicio y Nemoroso, porque la crítica lo ha interpretado también como parte de un «canto amebeo en sentido amplio» (Mateo 1991: 762) ${ }^{6}$. Teóricamente al menos, existe la posibilidad de que el canto amebeo esté formado no por una serie de pares adyacentes, como en la égloga tercera de Garcilaso, sino por un solo par de poemas, como en la virgiliana égloga VIII. Sin embargo, el toledano modifica significativamente la idea de contienda poética que subyace en su modelo al diluir la

${ }_{5}^{5}$ Sobre la procedencia virgiliana (égloga VII, 61-68) de la estructura correlativa, comenta Bayo (1970: 169-170): «Garcilaso reproduce en su octava la correlación. En general, distribuye cada pluralidad entre dos versos, menos 'y el laurel del rojo Apolo', que ocupa solamente medio verso por la elipsis (...). La recolección de Garcilaso alcanza a cuatro términos, uno más que en Virgilio». Luego añade, con respecto a la segunda octava del par: «Ha reducido los términos que se comparan de cuatro a dos: el fresno y el haya. El fresno es árbol de bosque. El haya señorea en medio del monte áspero».

${ }^{6}$ Por su parte, afirma B. Morros en la introducción a su edición (1995: 456): «El canto amebeo convertido en dos monólogos es corriente en la poesía pastoril; pero Garcilaso se atiene exactamente al esquema de la égloga VIII de Virgilio, como se ha venido señalando desde los comentaristas antiguos y como ha estudiado con grandes pormenores la crítica reciente». 
correspondencia entre los respectivos cantos de Damón y Alfesibeo: amor trágico-amor feliz ${ }^{7}$.

El contraste entre los dos monólogos de la égloga virgiliana falta en la primera de Garcilaso porque tanto el canto de Salicio como el de Nemoroso responden a situaciones más o menos trágicas, sin alteridad entre ellas. De hecho, el narrador tampoco introduce el canto de Nemoroso como respuesta al de Salicio: «Lo que cantó tras esto Nemoroso,/ decildo vos,/ Pïerides, que tanto/ no puedo yo ni oso» (vv. 235-237); mientras que Virgilio sí lo hacía con el de Alfesibeo: «Haec Damon; uos, quae responderit Aphesiboeus,/ dicite, Pierides: non omnia possumus omnes» (VIII, 62-63). Es decir, Garcilaso transforma el esquema responsivo original en otro sucesivo mediante el cual reúne o agrupa los dos cantos, sin establecer entre ellos relación de alteridad.

La primera égloga de Garcilaso compuesta hacia 1534 tuvo mucho éxito en la tradición poética posterior y, bajo su influencia, se realizan varias composiciones que no son cantos amebeos en realidad, aun cuando en ocasiones hayan sido calificados como tales. Por ejemplo, imita la disposición de la égloga garcilasiana Hernando de Acuña en su «Égloga y contienda entre dos pastores enamorados sobre cuál de ellos padece más pena: Silvano, que habiendo dicho la suya es maltratado, o Damón, que no la osa decir» (Prieto 1984: 129-130), ya desde el título alusivo al enfrentamiento dialéctico entre ambos pastores, en términos más argumentativos y racionales que emotivos.

Tampoco podemos considerar como amebeo la égloga de Diego Hurtado de Mendoza que comienza: «En la ribera del dorado Tajo», concebida como dos cantos sucesivos de Melibeo y Damón. Cierto que Hurtado de Mendoza imita ocasionalmente tanto el modelo garcilasiano de la égloga primera como el virgiliano de la octava, ya desde su inicio cuando repite la imagen tópica de la igualdad pastoril:

iguales en cantar y en responder, iguales en quejarse y con razón.

Olvidan los ganados el pacer, los montes inclinaron las alturas y pararon los ríos el correr (n. ${ }^{\circ}$ XVII, vv. 7-12).

Aunque utiliza el verbo «responder» procedente de la égloga virgiliana, no hay correspondencia ni alteridad entre el canto de Melibeo (que, en realidad, es una canción tal y como aparece al final en el envío) y el de Damón: mientras que aquél se lamenta por la muerte de Isea, éste acusa a la ingrata Marfira porque se ha casado con otro. No existe correspondencia métrica entre ambos

${ }^{7}$ Como dice V. Cristóbal, en la introducción a las Bucólicas de Virgilio (2000: 201): «El tema es (...) amoroso en ambos casos, pero mientras en la primera canción la conclusión es trágica, en la segunda la conclusión es feliz, y ahí reside el contraste exigido por el carmen amoebaeum». 
poemas, ni alteridad entre sus respectivos puntos de vista, por lo que no cabe considerarlo como amebeo, a pesar de las opiniones discrepantes de la crítica, en sentido afirmativo (Mateo 1991: 778) o negativo: «Ha mantenido el esquema estructural de la égloga VIII de Virgilio, que consta de dos largas quejas sucesivas — no amebeas - ; las de Damón, primero, y después, tras breve advertencia, la de Alfesibeo») (Bayo 1970: 175).

La alargada influencia de la égloga primera de Garcilaso se percibe con posterioridad en dos de las seis églogas compuestas por Fernando de Herrera, quien tampoco emplea el amebeo. La égloga «Salicio», que el poeta sevillano edita precisamente en sus Anotaciones (1580) garcilasianas como homenaje al toledano, está compuesta por dos cantos fúnebres sucesivos: de Alcón y luego de Tirsis, entre los cuales falta de nuevo la correspondencia y alteridad, incluso con respecto el número de versos que componen cada uno de los dos cantos puesto que el de Alcón consta de 37 tercetos (111 versos), mientras que el de Tirsis tan sólo tiene 27 (81 versos) $)^{8}$.

La discrepancia de opiniones en la crítica especializada sobre la existencia del amebeo puede hacerse extensiva a otros en los que se observa su evolución como el de Sireno y Silvano en La Diana (c. 1558), introducido directamente en el sexto libro mediante el siguiente comentario del narrador: «y los pastores comenzaron a cantar desta manera» (Montemayor 1996: 263). En el amebeo de Sireno y Silvano, que resulta novedoso con respecto al modelo clásico garcilasiano tanto por el poliestrofismo como por su lexaprén, los respectivos pares de estrofas alternadas no mantienen el contraste porque falta «la nerviosa adversación del canto contra canto» (Bayo 1970: 258). De manera general, Montemayor se distancia de la tradición virgiliana a la que Garcilaso permanece mucho más apegado, ya que en su poesía pastoril se percibe una fuerte impronta de la tradición de cancionero. Emplea también con preferencia el debate poético como el de los pastores y las ninfas, que remite a la tradición medieval de enfrentar dos principios opuestos: el agua y el vino, el alma y el cuerpo, etc., con predominio de la argumentación discursiva y lógica9

${ }^{8}$ La unanimidad de la crítica tampoco es absoluta en este caso: mientras que Ruestes (1989: 299-333) no alude al amebeo, Mateo (1991: 779) considera que sí lo emplea, tanto en la égloga «Salicio», como en la de Olimpio y Tirsis. En esta égloga, la más extensa de las seis, que comienza: «El lastimoso canto y el lamento», se introduce primero el monólogo de Olimpio, quien llora la ausencia de Galatea, y luego el de Tirsis, quien se lamenta por el olvido de Leucipe (Ruestes 1989: 217).

${ }^{9}$ Sobre el debate poético de ninfas y pastores, comenta Juan Montero en su edición de La Diana (1996: 172n): «El desarrollo del poema no responde al esquema ni al espíritu del canto amebeo pastoril [...] sino más bien al viejo modelo trovadoresco del debate en estrofas alternas»; en cambio, Pérez-Abadín (2012: 44n) se refiere al «canto amebeo en liras entre ninfas y pastores», cuando analiza las églogas de Pedro de Padilla, como la II y la XII, en las que se incluyen sendos amebeos (ibid.: 64-65 y 246-267). 
Al margen de La Diana, el resto de las églogas de Montemayor incluido en sus dos cancioneros profanos, se relaciona de nuevo más con la tradición de los debates y cuestiones de amor que con el amebeo propiamente dicho, sobre todo la égloga I del «amor fino» que dice sentir Lusitano, y la égloga II, en la que Olinea y Solisa debaten sobre si es mayor mal la ausencia del amado o no conocer el Amor, ambas en el Cancionero de 1554; ya que en la égloga III del Cancionero de 1562, se relatan varias historias amorosas entre las que figura la de Diana-Sireno, lo que «parece un primer paso, una especie de ensayo para su definitiva configuración en La Diana» (Mateo 1991: 323). Tampoco es característica del amebeo la dualidad que aparece al final de la égloga IV del Cancionero de 1562, aun en contra de la opinión de Pérez-Abadín (2004: 211), puesto que, a pesar de apoyarse en «la alternancia de las fórmulas optativas, Mal haya el que y Bien haya el que, reforzadas por la anáfora y el paralelismo», existe un contraste lógico entre los respectivos puntos de vista de los pastores Pireno y Silvio, como se ve desde el primer par de estrofas:

PIRENO ¡Mal aya el que se fía en esperança,
quando el remedio ve estar dudoso!
¡Mal aya quien no teme la mudança
si a dicha en algún tiempo está en reposo!
¡Mal aya el que se fía en lo que alcança
pues nunca estado vi más peligroso
que estar un amador tan confiado
que no piense perder lo que ha ganado!

SILVIO ¡Bien aya el que es tan firme en sus amores, que no es subjeto a tiempo ni a Fortuna! ¡Bien aya el que no spera más favores que ver que su pastora es sola una! ¡Bien aya el que entre celos y temores su fe pone más alta que la luna, que en fin, el buen amor, quando es perfeto, no debe a cosa destas ser subjeto! (1996: 697).

A diferencia de Pireno y Silvio, la alteridad del amebeo garcilasiano de Tirreno y Alcino no se basa en un contraste argumentativo, sino puramente emocional desarrollado en el amebeo de la égloga garcilasiana mediante una serie de imágenes asociadas al mundo natural que rodea a los dos pastores. Aunque no se encuentra en Montemayor, el modelo más clasicista de la égloga tercera de Garcilaso se mantiene en otros poetas, como Francisco de la Torre, quien incluye dos ejemplos (églogas I y VIII) dentro de las ocho églogas que llevan por título «La bucólica del Tajo», en claro homenaje al poeta toledano (Estévez 2002: 314-324 y Pérez-Abadin 2009), agrupadas en el cuarto y último libro de sus Obras no editadas hasta 1631 por Francisco de Quevedo. Al final de su primera égloga («Dafnis»), Francisco de la Torre introduce un canto 
amebeo entre los pastores Títiro y Palemón, inspirado literalmente en la tercera garcilasiana. También imita su forma métrica y los motivos pastoriles, pues el amebeo de «Dafnis» está compuesto por cinco pares de octavas en las que Títiro pondera su amor por Cintia, mientras que Palemón hace lo propio con Dafnis (vv. 241-320). Previamente, el narrador de la égloga describe minuciosamente el entorno primaveral en el que tiene lugar la escena pastoril, a orillas del río Tajo, con abundancia de flores y árboles (vv. 25-48) que adornan los «alegres prados». La belleza del locus amoenus contrasta con la desesperación amorosa de los pastores ya que, como consuelo de sus respectivas penas amorosas, Títiro y Palemón deciden cantar juntos el amebeo.

En el primer par (vv. 241-256), Títiro alaba la belleza de su pastora mediante una serie de comparaciones extraídas de la naturaleza primaveral: flores, rosas, aurora, en las que destaca su colorido; mientras que Palemón imita la serie de comparaciones, en una estructura correlativa. En el segundo par, cada una de las dos estrofas se abre con un vocativo dirigido in absentia a Cintia o a Dafnis, las amadas respectivas de ambos pastores. Mientras que Títiro pregunta a Cintia: «¿por qué un amor tan grande desconoces?» (v. 264), Palemón utiliza un imperativo para solicitar de Dafnis el remedio a sus cuitas amorosas: «remedia mi dolor entristecido» (v. 272). Otra serie de comparaciones tomadas de la naturaleza aparece en el par siguiente: Títiro pondera el «desdén altivo airado» (v. 277) de Cintia, mientras que Palemón se refiere al «rayo... de su luz serena» (v. 288), por la mirada de Dafnis. En los dos últimos pares, la semejanza con la égloga III de Garcilaso se hace todavía más evidente en las propias imágenes poéticas, cuando Títiro compara la presencia de su pastora con los efectos de la primavera: «dando su luz a todo lo criado» (v. 294) y, en sentido alterno, Palemón subraya los efectos benéficos cuando «sale mi sol resplandeciente» (v. 301); luego se compara una serie de árboles con el árbol preferido por cada una de las dos amadas: el plátano y el «líbano» (v. 319). Como el de Garcilaso, el amebeo de Francisco de la Torre respeta la alternancia en cuanto a los sentimientos que exponen ambos pastores, pues cada uno canta a su amada respectiva, si bien no existe el contraste y la dualidad en todos los pares de octavas ya que Palemón se limita en ocasiones a repetir con variantes los motivos poéticos que propone Títiro $^{10}$.

El otro amebeo de «La bucólica del Tajo» aparece al final de la égloga VIII, titulada «Lícida». Escrita en estancias, comienza con una descripción del amanecer en «la sazón del otoño seco» (v.17). El narrador describe la llegada del

${ }^{10}$ Esta diferencia con respecto al modelo garcilasiano también la señala Mateo (1991: 770) cuando dice de este canto amebeo: «va progresando alrededor del mismo tema, y desde la misma perspectiva: si uno adopta la actitud positiva, el otro le secunda; cuando es negativa, la del colocutor también». 
«ausente pastor Montano», quien se refugia en una cueva a orillas del río Tajo; hace una pormenorizada descripción de la cueva habitada por las ninfas y bañada por el «sacro río». A continuación, el narrador cede la palabra a Montano, quien canta su desesperación amorosa por la ausencia de Lícida hasta que llega un pastor amigo y, «al son de su zampoña acordado», se intercala el amebeo entre Montano y Ergasto, seguido de una estancia final como cierre del poema que es evidente eco de Garcilaso (égloga I, vv. 408-413):

\author{
No pusieran tan presto fin al canto, \\ que el solitario y solo monte oía, \\ los dos tristes y míseros pastores, \\ si el negro manto de la noche fría \\ del triste reino del eterno espanto \\ no eclipsara los delios resplandores (vv. 206-210).
}

Este amebeo de Francisco de la Torre se compone de tres pares de estancias, en las que Montano se dirige a su amada Lícida y Ergasto a Fílida. La imagen de «el blanco lirio y la purpúrea rosa» (v. 144), tomada de la primera égloga garcilasiana casi literalmente: «el blanco lirio y colorada rosa» (I, 104), le sirve a Montano para ponderar la belleza de Lícida, aunque la pregunta final lleva aparejada una exaltación del deseo que no encuentro en los pastores garcilasianos: «¿qué me puede mostrar el claro cielo,/ si en sólo mi deseo/ tengo puesta mi gloria y mi consuelo?» (vv. 148-150). Ambas estancias mantienen el paralelismo sintáctico: «Lícida mía, más que el Sol hermosa»... (v. 140); «Fílida mía, más resplandeciente/ que al salir el Oriente la mañana» (vv. 151-152); hasta la oración condicional. En el segundo par, Montano se refiere a la ausencia de Lícida, mientras que Ergasto habla del «desdén altivo» (v. 174) de Fílida. En el tercero y último, de nuevo con paralelismo sintáctico, Montano y Ergasto exaltan la eternidad y firmeza de su amor: «hasta que el cuerpo y el alma se despida» (v. 194); o «mientras el reluciente dios dorado/ siguiere su curso» (v. 205).

\title{
Entre Cervantes, Lope de Vega y Góngora
}

A partir del modelo fijado por Garcilaso, hemos visto dos variantes del canto amebeo: una más clasicista en la línea de «La bucólica del Tajo»; y otra, asociada a La Diana de Montemayor y continuada en otros libros de pastores como el de Gil Polo Diana enamorada (1564), en la que el «canto alternado se ha transformado en una forma estrófica del diálogo al desaparecer la tensión contrapositiva» (Bayo 1970: 273). El mismo proceso se observa en los dos amebeos incluidos en La Galatea (1585) de Cervantes, quien imita entre otros el modelo de Montemayor en su libro de pastores que dedica al futuro cardenal 
italiano Ascanio Colonna ${ }^{11}$. Con el relato pastoril cervantino, vamos a ver una serie de autores que a partir de la década de los ochenta supone un cambio poético hasta que en 1613 se difunden los dos poemas mayores de Góngora: la Fábula de Polifemo y Galatea y las Soledades marcando un antes y un después en la poesía cultista de la época. Además de los dos amebeos cervantinos, analizaremos la evolución del canto alterno especialmente en los respectivos ejemplos de Lope de Vega y Luis Carrillo y Sotomayor, junto con los que incluye Góngora en sus Soledades.

En el primer amebeo de La Galatea, introducido nada más iniciarse la narración, los dos pastores Elicio y Erastro cantan su amor no correspondido por la misma pastora, como en el caso de Sireno y Silvano en La Diana. Elicio le propone amistosamente al otro pastor cantar un amebeo: «Tú, al son de tu zampoña (...) yo, al de mi rabel» (Cervantes 2014: 28). La mención del rabel, instrumento musical de cuerda, frente a los instrumentos de viento como la zampoña típicos de la bucólica y de los pastores garcilasianos, aleja a Cervantes de la tradición pastoril clásica: «No se hizo de rogar Erastro; antes, con muestras de estraño contento por verse en tanta amistad con Elicio, sacó su zampoña y Elicio su rabel; y, comenzando el uno y replicando el otro, cantaron lo que sigue» (Cervantes 2014: 29).

El amebeo está compuesto por cuatro pares de octavas, ya que el quinto queda sin respuesta (otra novedad cervantina) por la aparición inesperada de un pastor, el cual interrumpe el canto: «Ya se aparejaba Erastro para seguir adelante en su canto, cuando sintieron, por un espeso montecillo que a sus espaldas estaba, un no pequeño estruendo y ruido» (Cervantes 2014: 32). Comienza el amebeo Elicio invocando al «ingrato Amor» y responde Erastro, con una referencia a las «saetas de oro» que ha sentido al ver a Galatea. No hay contraste positivo/negativo entre los respectivos puntos de vista de los pastores, más próximos al modelo de Montemayor que al de Garcilaso, pues ambos se refieren a la misma situación poética (la vista de Galatea) en términos muy semejantes, sin que se produzca entre ellos la alteridad característica del amebeo.

En el segundo par, Elicio interpela directamente al amor, formulando una serie de preguntas sobre los efectos inexplicables que causa en el alma del amante; por su parte, Erastro se refiere, mediante la imagen del espejo roto, a los «cuidados» que causa en su alma «un cuidado crüel» (v. 30). Ambos pastores expresan de nuevo una situación emocional semejante, sin que exista alteridad entre sus respectivos cantos. En el siguiente par de octavas, Elicio se

${ }^{11}$ Cervantes cultivó la amistad de hombres de letras que formaban parte del círculo en torno a Ascanio Colonna (Marín Cepeda 2015: 51-58 y 410-416), como Pedro de Padilla y Gálvez de Montalvo, con quienes comparte el gusto por las églogas y relatos pastoriles en un entorno de relaciones cortesanas que tienen su reflejo en la ficción, donde Pedro Laínez aparece en el pellico de Damón, o Diego Hurtado de Mendoza en el de Meliso. 
refiere a la ceguedad que le ha causado el «invisible fuego» después de ver la «blanca nieve y colorada rosa» (v. 33), expresión tomada de nuevo de la primera égloga garcilasiana: «el blanco lirio y colorada rosa» (I, 104), mientras que Erastro alude a la «niebla» en que le han sumido las «mil gracias» de su amada: «que no tienen cuento,/ niebla me han hecho al amoroso viento» (vv. 47-48). Tampoco se respeta la contraposición en el último par, ya que no se mantiene la correspondencia entre la octava en que Elicio menciona una típica serie de contrarios: "Yo ardo y no me abraso, vivo y muero;/ estoy lejos y cerca de mí mismo;/ espero en un solo punto y desespero»... (vv. 49-51), y la octava de respuesta en la que Erastro, de manera excepcional, interpela directamente a su compañero para plantearle una promesa: «Yo te prometo, Elicio»... (v. 57), quien, su vez, también le responde. Queda rota por completo la alternancia del amebeo al establecerse entre ambos un diálogo explícito al margen de la contienda.

Cervantes introduce otro ejemplo de reutilización del mismo procedimiento al final del libro IV de La Galatea, cuando los mismos pastores Elicio y Erastro cantan una vez más su poco afortunado amor por la protagonista epónima, ahora en presencia de su amada pastora: «desta manera comenzó a cantar Elicio, y a responderle Erastro» (Cervantes 2014: 273). Los cuatro primeros pares están compuestos también en octavas, como el amebeo del primer libro, pero en el cuarto y último Cervantes utiliza endecasílabos de rima interna sin mantener la necesaria correspondencia entre los seis endecasílabos de Elicio y los catorce puestos en boca de Erastro. De acuerdo con las dos innovaciones que ya hemos visto utilizadas en La Diana de Montemayor, el amebeo cervantino se caracteriza no sólo por su polimetría, sino también por el uso del lexaprén que se mantiene a lo largo de toda la composición. El lexaprén favorece la repetición de la misma imagen: en el primer par, los efectos que causa la vista de la amada en cualquiera que la contemple; en el segundo, los efectos contradictorios que la vista de la «dulce enemiga» (v. 26) provoca en ambos pastores enamorados; en el tercero, la perfección de Galatea: «cordura sin igual, rara belleza/ donde más se estremó naturaleza» (vv. 39-40); y, por último, el desdén que manifiesta hacia sus dos enamorados: «¿qué gusto, pues, qué gloria o bien se ofrece,/ do mengua la esperanza y la fe crece?» (vv. 63-64). Los puntos de vista de ambos son complementarios, al modo de Montemayor más que de Garcilaso.

Cervantes muestra su preferencia por las innovaciones que introduce Montemayor en La Diana al separarse de la tradición más clasicista de la bucólica. Junto con los dos amebeos de La Galatea, hay otro ejemplo posterior en $L a$ Gitanilla, incluida en sus Novelas ejemplares (1613), fuera del marco pastoril en el que habitualmente se introduce el procedimiento. A pesar de ello, no hay duda ninguna sobre la pertenencia del canto de Andrés y Clemente a la serie literaria aquí estudiada, como lo demuestra el comentario con el cual introduce el narrador la composición: «sentados los dos, Andrés al pie de un alcornoque, 
Clemente al de una encina, cada uno con su guitarra, convidados del silencio de la noche, comenzando Andrés y respondiendo Clemente, cantaron estos versos» (Cervantes 2001: 91). Como instrumento «picaresco» (al que también se muestra aficionado el Loaysa de El celoso extremeño), la guitarra responde al nivel social que finge Andrés, disfrazado de gitano a pesar de su origen noble. Sin embargo, quedan restos de la ambientación pastoril en los árboles bajo los cuales se sientan los dos improvisados poetas: el alcornoque y la encina (que inspira a don Quijote su discurso a los cabreros), pero sobre todo en la fórmula: «comenzando... respondiendo» ${ }^{12}$.

Está compuesto el amebeo de tres pares de estrofas, con ocho versos cada una. En todas ellas, se pondera la belleza de Preciosa, sin una oposición entre los respectivos puntos de vista de Andrés y Clemente, usando también del lexaprén. Desde el punto de vista temático, se caracteriza la alabanza de la gitanilla que da título a la novela por varios motivos neoplatónicos como el de la hermosura humana que refleja la belleza del cielo y el de la armonía cósmica de las esferas con su «música callada». Las dos voces se complementan, pero no establecen alteridad ni contraste entre ellas cuando exaltan la belleza de Preciosa. Mediante las innovaciones que introduce el autor del Quijote en el amebeo, se separa de la tradición clasicista de Virgilio a Sannazaro y Garcilaso, a pesar de las resonancias clásicas y pastoriles que todavía mantiene. Estas innovaciones pueden ser también un síntoma de la renovación que se produce en la transición del siglo XVI al XVII.

Las novedades del canto amebeo con respecto al modelo garcilasiano se observan también en la Arcadia (1598) de Lope de Vega, libro de pastores dentro del género inaugurado por Montemayor que se inspira en los amores del quinto duque de Alba. Su variedad métrica, como explica Felipe B. Pedraza Jiménez (2003: 55): «se corresponde con la diversidad de géneros, temas, tonos y acentos poéticos. Lope acoge y renueva en cierta medida las tradiciones que llegan a finales del siglo XVI». Acorde con esta renovación, ensaya Lope el procedimiento del amebeo en la égloga del libro primero que, como dice Yolanda Novo (1998: 260): «es la única estructurada como un canto amebeo, cuyo carácter responsivo se refuerza al repetirse íntegramente igual el verso final del recitado de un pastor en el que inicia el otro». Aparece el amebeo después de que el narrador describa la «pastoral Arcadia» que, ya desde el propio título de la obra, evoca el modelo de Sannazaro: «Este es, pastores del dorado Tajo, el teatro de mi historia; que ya sabéis que es obligación del que comienza alguna la descripción del lugar donde sucede» (Vega 2012: 180).

12 Como anota J. García López en su edición (2001: 90n), es una expresión «de resonancia clásica afín al bucolismo virgiliano, con influencia de Garcilaso y Jorge de Montemayor». 
El amebeo de Galafrón y Leriano viene a interrumpir una escena amorosa entre Belisarda y Anfriso, los auténticos protagonistas ${ }^{13}$. Al final del mismo, subraya el narrador la peculiar naturaleza del canto mediante la habitual fórmula virgiliana, aunque innova cuando señala la diferencia de edad entre ambos pastores: «En tanto que Galafrón cantaba y Leriano respondía, pastores de la Arcadia aunque desiguales en edad conformes en pensamientos e igualmente aborrecidos» (Vega 2012: 197). Tampoco mantiene la dualidad típica del amebeo clásico, ya que Galafrón y Leriano expresan su desesperación amorosa ante la crueldad de Belisarda con un tono parecido. La semejanza en la forma de expresar los dos pastores su desesperación amorosa viene de nuevo favorecida por el uso del lexaprén, como en los amebeos de La Diana (Sireno y Silvano) y de La Galatea (Elicio y Erastro). El primer par de octavas mantiene el paralelismo sintáctico mediante la comparación de la furia y el desdén de la pastora con una serie de elementos tomados de la Naturaleza. En el segundo, se refieren ambos pastores a los celos que les causa su amor no correspondido. En el tercero, prometen venganza por el olvido de su pastora. En el cuarto y último, otra serie de elementos tomada de la Naturaleza les sirve de comparación para calificar la conducta de Belisarda.

Además del amebeo propiamente dicho, hay otra égloga dialogada que protagonizan Galafrón y Leriano, ya en el libro II de la Arcadia, en la que ambos cantan en tercetos esdrújulos su desesperación por la partida de Belisarda. Algunos de los intercambios de estrofas se asemejan al canto amebeo sin que de nuevo aparezca la idea de alteridad o de contraste. Más que responderse, los dos pastores insisten en la formulación de la misma idea en cada uno de los pares sucesivos, como en el siguiente:

GALAFRÓN ¿Qué guerra en Cannas, en Farsalia o Púnica, como la de mi alma vio el Armígero que es diamante su celada y túnica?

LERIANO ¿Qué guerra te ha igualado, amor belígero?

Dígalo el dios tonante por Deólida, Apolo y Marte, y nuestro Pan cornígero (Vega 2012: 349).

Sin embargo, pocos años después de haber publicado la Arcadia, en la segunda parte de sus Rimas (1604), incluye Lope un ejemplo más acabado de canto amebeo, en su égloga «Albanio» dedicada precisamente al duque de

${ }^{13}$ Sobresale el protagonismo de Anfriso, disfraz pastoril del quinto duque de Alba, la difusión de cuyos amores fue el motivo principal del éxito del relato, según D. Finello (2014: 87): «La Arcadia se publicó varias veces en el siglo XVII (no menos de 20), hecho que prueba la admiración general por haber revelado las aventuras amorosas de su protagonista, Antonio Álvarez de Toledo, duque de Alba, sometiendo su reputación al escrutinio público». 
$\mathrm{Alba}^{14}$. El narrador presenta una competencia amorosa entre dos pastoras, Antandra e Ismenia, enamoradas de Albanio. En esta ocasión, el amebeo sí mantiene la dualidad, ya que mientras Antandra expresa su alegría por el amor (si bien fingido) de Albanio, Ismenia lamenta su desamor (también fingido por Albanio: «cuando más en el alma la adoraba»). El contraste de los respectivos puntos de vista de las dos pastoras se mantiene en sus respectivos estribillos: «Por esto Ismenia triste lamentaba,/ Antandra alegre bendecía los cielos», aunque presenta varias novedades con respecto al modelo garcilasiano. En primer lugar, el amebeo de Antandra e Ismenia está puesto en boca de dos pastoras, mientras que en la tradición clásica suelen ser pastores. En segundo lugar, no media la propuesta de cantar y responder, ya que ninguna de las dos pastoras sabe que la otra está oyéndola.

El amebeo introducido en la égloga de Albanio, de acuerdo con su variante clasicista que mantiene estrictamente la dualidad, se desarrolla a lo largo de cuatro pares de estancias mediante el contraste que se produce en el par inicial entre los «Álamos blancos» frente a los: «Álamos negros», ya que la segunda estancia (vv. 105-120) reproduce casi literalmente la fraseología de la primera manteniendo la oposición («verde puro» frente a «verde escuro»): «marchita caiga quien de amor se prive/ mientras Albanio con Antandra vive» frente a «de lo que fuere amor todo se prive,/ mientras Albanio sin Ismenia vive». De esta manera, cada uno de los sucesivos pares de estancias gira en torno a la invocación de cuatro series homogéneas tomadas de la naturaleza: álamos, roble, vides y yedras en el primer par; aves y tórtolas en el segundo; fieras, leones, tigres y ciervas en el tercero; y peces, en el cuarto. «Albanio» no es la única muestra del género que incluye Lope en la segunda parte de sus Rimas, pues también añade las églogas «Eliso» (un monólogo amoroso del pastor por Lucinda) y «Farmaceutria» (un diálogo entre Meliso y Tirso), en las que, no obstante, falta la utilización del amebeo. Con posterioridad a la publicación del poemario, durante el llamado ciclo de senectute según la expresión acuñada por Juan Manuel Rozas (1990), Lope de Vega volvería a escribir églogas ${ }^{15}$.

${ }^{14}$ Felipe B. Pedraza (2003: 112): «Sigue los moldes garcilasianos. Tras una introducción del narrador, se presenta el canto amebeo de Antandra (trasunto de Catalina Enríquez), que canta sus amores, y de Ismenia (álter ego de Mencía de Mendoza), que llora sus desdenes». En su edición de las Rimas (Vega 1994: 92), comenta también: «Los elementos de la naturaleza van a simbolizar alternativamente la alegría de Antandra y el pesar de Ismenia. Las reminiscencias garcilasianas son constantes. El canto es una suerte de amplificación de algunos motivos de la Égloga I. Las dos primeras estancias desarrollan los versos 240 y 243 con los motivos del árbol (aquí álamos) y de la hiedra (aquí transformada en amorosa vid)».

15 De hecho, conservamos cinco églogas agrupadas en torno a la edición póstuma de La vega del Parnaso (1637): «Égloga Panegírica al epigrama del serenísimo infante Carlos», «Égloga en la muerte de... Paravicino», «Amarilis», «Filis» y «Felicio», ya que no podemos considerar dentro del género la llamada «Égloga a Claudio», en realidad una epístola con un «fuerte acento elegíaco» (Novo 1996: 250; Montero 1996). 
Aunque disminuye el cultivo del género bucólico durante el siglo XVII, todavía continúa su escritura asociada a la tradición cultista, uno de cuyos precursores es Luis Carrillo y Sotomayor. Compone a principios de siglo dos églogas, en la primera de las cuales introduce un amebeo protagonizado esta vez por dos pescadores, Fabio y Delio, de acuerdo con la variedad de la égloga piscatoria cuya tradición se puede remontar hasta los idilios de Teócrito, pasando por las eclogae piscatoriae de Sannazaro y las canzioni pescatorie de Tansillo: «La acomodación del género en España contaba ya con eximios precedentes, dado que Jerónimo de Lomas Cantoral había traducido tres composiciones de Tansillo» (Ponce Cárdenas 2001: 87) ${ }^{16}$.

Comienza la égloga piscatoria de Carrillo y Sotomayor con una dedicatoria epistolar al conde de Niebla que da paso a un diálogo inicial entre los pescadores, sentados a orillas del mar y protegidos del sol por «aquesta haya», como dice Delio con un eco evidente del Títiro virgiliano. La llegada del otro pastor propicia la invitación al canto amebeo que propone Fabio, cuando dice: «Mas, pues descansa el brazo de la caña,/ no descanse tu lira» (Carrillo 1990: 123). Está formado el amebeo por dos pares, compuesto cada uno por cinco estrofas aliradas de seis versos. Después del canto alterno de los dos pescadores, el narrador concluye el poema con una octava final, en la que afirma, con evidente eco virgiliano: «Esto Delio cantó, y esto, amoroso,/ Fabio le respondió» (ibid.: 124). Carrillo no sólo respeta estrictamente el paralelismo sintáctico y estrófico entre las estrofas que integran cada uno de los dos pares, sino que mantiene la dualidad entre ellas, como era obligado en la modalidad clasicista del amebeo que proviene de la égloga tercera garcilasiana. En el primer par, contrasta la «aspereza» de Celia (que Fabio compara con los efectos terribles de una tormenta marítima) y la «beldad» de Belisa (que Delio asemeja a la serenidad que proporciona el sol cuando triunfa sobe la «noche escura»); en el siguiente par, Fabio parangona el desamor de Celia con la frigidez del invierno y Delio, el amor de Belisa con el verano.

Otro fenómeno característico del amebeo de Carrillo es la intensidad que adquieren las descripciones tomadas de la naturaleza, hasta el punto de considerarse como una constante en la evolución de la égloga perceptible durante el Barroco $^{17}$. Por ejemplo, la égloga tercera de Soto de Rojas ha llamado la aten-

16 De aquí en adelante, cito la égloga piscatoria de Carrillo por la edición de Rosa Navarro (1990: 223-228), aunque tengo en cuenta la edición de Angelina Costa (1984: 121124).

17 Con respecto al propio Carrillo, se trata incluso de una tendencia general que se percibe en toda su obra poética, como dice Angelina Costa en su edición (Carrillo 1984: 36): «En su desarrollo predomina lo descriptivo y narrativo sobre lo lírico, y es, además, un magnífico pretexto para mostrar habilidades retóricas». No sería difícil traer a colación ejemplos de la exuberancia barroca en las descripciones paisajísticas; por ejemplo, en la égloga tercera del Desengaño de amor en rimas (1623) de Pedro Soto de Rojas que, según 
ción de la crítica precisamente por la intensidad con la que aparecen en ella descripciones de la Naturaleza, que anticipan su poema paisajístico posterior, más conocido: el Paraíso cerrado para muchos, jardines abiertos para pocos (1652). Son también prolijas las descripciones tomadas de la Naturaleza en los dos poemas mayores de Góngora, el Polifemo y las Soledades, divulgados desde 1612-1613 que, aunque no pueden considerarse estrictamente como églogas, están muy relacionados con el género bucólico.

La filiación pastoril es evidente en el caso de la Fábula de Polifemo y Galatea, ya desde la primera octava, cuando dice el narrador: «culta sí, aunque bucólica Talía» ${ }^{18}$. El mismo argumento que sirve de base a esta fábula mitológica de Góngora, aunque derivado principalmente de las Metamorfosis ovidianas, se relaciona también con la tradición pastoril, pues aparece en los Idilios VI y XI de Teócrito y proyecta algunos ecos suyos en la égloga segunda de Virgilio. Sin embargo, el motivo de la fábula se vincula en el poema gongorino al tema de la abundancia natural, que corresponde en gran parte a la fertilidad agrícola y ganadera de Sicilia en la que se ambienta el poema: «en una dimensión en la que lo arcádico asimila los componentes del mito de la Edad de Oro y del Edén» (Ruiz Pérez 2002: 406). El narrador aparece perfectamente distanciado y diferenciado del pastor Cíclope, quien se encarga de entonar el canto pastoril.

La distancia entre el mundo pastoril y el punto de vista narrativo, consustancial a la relectura del género bucólico que hace Góngora, reaparece de otro modo en el misterioso «náufrago y desdeñado sobre ausente» que protagoniza las Soledades como peregrino cuando llega de manera accidental al mundo rústico en el que encuentra refugio. El desarrollo de la renovación poética gongorina culmina en las Soledades cuya filiación pastoril, aunque menos obvia que en el Polifemo, resulta también perceptible en varios pasajes dentro de su mezcla de estilos; por ejemplo, en el «bienaventurado albergue» pastoril de la Soledad primera.

palabras de Aurora Egido en su edición, constituye «una cornucopia de la variedad de la Naturaleza, desplegándose en una detallada enumeración de frutos que ella contiene y que son una continua llamada a los sentidos» (Soto de Rojas 1991: xlv). Las cuatro primeras églogas del Desengaño cuentan la aventura amorosa de Fenixardo; hay una quinta égloga añadida en la segunda parte, ya sin relación con la historia amorosa previa integrada en un cancionero petrarquista (Toro Valenzuela 2002). La predilección por la naturaleza «pródiga y sensorial» se ha considerado también como un rasgo típico en la trayectoria de poetas como Luis Barahona de Soto (Égloga de las hamadríades) y Pedro Espinosa, que la crítica asocia al grupo antequerano-granadino (Lara Garrido 1994: 257-260).

${ }_{18}$ Explica Ponce en su edición: «la contraposición de epítetos incide sutilmente en la naturaleza híbrida del poema, ya que los cauces venerables de la mitología y el estilo elevado del mismo lo vinculan a la tradición épica (en la singular modalidad conocida como epilio), en tanto que la condición pastoril del cíclope y la ambientación campestre lo relacionan con el entorno de las Bucólicas (églogas)» (Góngora 2010: 179). 
En lo que concierne al procedimiento del amebeo, es necesario señalar que Góngora introduce dos cantos alternos en los cuales se percibe también el esfuerzo de innovación que lleva a cabo el poeta cordobés con respecto a la tradición clásica en la que inscribe su producción poética. El primero aparece durante el tercer día, cuando el peregrino de las Soledades asiste a la boda serrana. Dos coros alternos de «zagalejas» y de «garzones» reciben a los novios entonando un canto nupcial, con las preceptivas invocaciones a Himeneo ${ }^{19}$. Los pares de «El dulce alterno canto» (Soledad 1., , v. 845) se suceden en estrofas de trece versos; el coro primero de garzones canta al novio, mientras que el segundo formado por las zagalas canta a la novia (vv. 767-844). Los tres pares de estrofas comienzan con la invocación: «Ven, Himeneo»; y al final de cada semicoro, repiten el estribillo: «Ven, Himeneo, ven; ven, Himeneo». Se trata de un canto responsivo que Góngora hace derivar de la tradición clásica del epitalamio, asociada a la fecundidad, en el marco nupcial de la boda serrana.

Los dos coros del epitalamio no establecen la competencia poética característica del amebeo que sí se produce cuando, también en las Soledades, el peregrino escucha las quejas de amor de los pescadores Micón y Lícidas, a lo largo de cinco pares de estrofas de siete versos cada una (Soledad 2. , , vv. 542611). Nos encontramos ante la variedad de égloga piscatoria cultivada también por Carrillo y Sotomayor, equivalente a la pastoril ${ }^{20}$. Después de que el peregrino se refugia en una isla, acogido por los pescadores que viven con seis hermanas y su anciano padre, a la llegada de la noche, oye el canto alterno que desde una barca entonan Lícidas y Micón enamorados, respectivamente, de Leucipe y Cloris. Tras oír el canto amebeo, el peregrino intercede por los pescadores y el anciano los acepta como yernos. En el primer par, Lícidas invoca a su «barquilla», a la que compara con la «cuna de mi edad primera» y luego con una «tumba»; mientras que Micón se refiere a su «leño» como «nadante urna». En el segundo, Lícidas evoca su encuentro con Leucipe a la que contempla buscando «rugosas veneras»; mientras Micón evoca, a su vez, las «prisiones» que le causa su amada Cloris. No hay en estos dos primeros pares de

${ }_{19}$ El canto remite el poema de Catulo al que alude J. Ponce Cárdenas (2001: 97): «La disposición en coros enfrentados se remonta al carmen LXII de Catulo, de donde procede asimismo la reiteración ritual: Hymen o Hymenaee, Hymen ades o Hymenaee!».

${ }^{20}$ Como dice Robert Jammes (1987: 335): «Podemos calificar como piscatorias a las poesías en las que a los pastores tradicionales de la pastoral reemplazan pescadores. Dejando de lado este cambio en la elección del disfraz, esas dos venas literarias son en principio semejantes, puesto que, tanto una como otra, tienen esencialmente por finalidad sacar a escena enamorados que exhalan sus quejas melodiosas en medio de un decorado natural y, si puedo decirlo, profesional, que toman constantemente como punto de referencia». Cita como antecedente de la modalidad piscatoria de Góngora algunos Idilios de Teócrito (como el XXI, de dudosa atribución) y las églogas de Sannazaro, tanto en la Arcadia como en sus églogas piscatorias (ibid.: 334-335n). 
estrofas oposición entre lo que dice cada uno de los pastores, sino paralelismo complementario en sus respectivas situaciones.

La alternancia de la dualidad propia del amebeo se manifiesta con claridad en el siguiente par, pues si Lícidas pondera su propia belleza cuando ve su imagen en la laguna (de acuerdo con un motivo que se remonta a los Idilios de Teócrito), el otro pescador, Micón, rechaza que el espejo del agua pueda hacer justicia a su figura. Se mantiene de nuevo el contraste alterno en el cuarto par, pues se opone la cabaña de Lícidas adornada de conchas y la cabaña de Micón, adornada de corales. Y también durante el último par, con variantes sobre el tópico carpe diem, cuando Lícidas le pide a su amada que goce de su juventud y Micón le advierte sobre la fugacidad del tiempo: anverso y reverso de un mismo tópico. También la alusión del narrador de las Soledades a las «dulcísimas querellas/ de pescadores dos, de dos amantes/ en redes ambos y en edad iguales» (vv. 516-518) remite al conocido planteamiento de la virgiliana égloga VII: «ambo florentes aetatibus, Arcades ambo,/ et cantare pares et respondere parati» (VII, 4-5), a través de la tercera égloga (vv. 301-303) de Garcilaso obviamente.

\section{Poesía Y diÁlogo}

El amebeo comparte con las variedades del diálogo en prosa su pertenencia a la ficción o mímesis dialógica a través de la caracterización de los interlocutores que provienen, en el caso de la égloga, del mundo pastoril. Sin embargo, la especificidad del procedimiento amebeo aquí analizado se define por las especiales características de su forma poética: «au profit d'une fonction qui ne peut plus des lors être qualifiée que d'esthétique, et par laquelle le message s'immobilise dans l'existence autosuffisante de l'oeuvre d'art» (Genette 2004: 103). El carácter intransitivo de la «dicción», frente a otras modalidades de la poesía polémica, sirve para definir la tradición del amebeo que, como hemos visto, está ligada a la proyección que alcanza el canto de Tirreno y Alcino al final de la égloga de Garcilaso que, a su vez, deriva de Virgilio:

La figura del pastor inmerso en un mundo arcádico, perfectamente definida en las Bucólicas, es, sin duda, la deuda principal que el Renacimiento tiene con Virgilio [...]. A partir de Garcilaso, la tradición lírica no suele acudir directamente a Virgilio sino al poeta toledano, a los italianos o a la novela pastoril (Blecua 2006: $157-159)^{21}$

21 Álvaro Alonso (2002: 84) afirma en este mismo sentido: «No es Encina, sino Garcilaso, como casi siempre, quien abre el camino a la poesía posterior. Sus tres églogas son un modelo tan influyente que oscurecen incluso a Virgilio: las Bucólicas no parecen haber tenido una gran influencia directa en el desarrollo del género en España, ya que los poetas prefieren seguir a su precursor inmediato en lugar de remontarse directamente al original 
Además de su pertenencia a una tradición literaria común, los amebeos analizados comparten una serie de rasgos condicionados por la alteridad presente en los sucesivos pares de estrofas. La dualidad alterna implica que el pastor que interviene en segundo lugar está obligado a decir lo contrario o bien a sobrepujar la intervención precedente. La variante clasicista recuperada por Garcilaso se desarrolla en los mejores amebeos mientras que las dos voces pastoriles de la menos clasicista, derivada de Montemayor, son repetitivas antes que responsivas, por lo que se puede llegar a diluirse la idea de alteridad hasta el punto de asimilarse a otras modalidades de la poesía dialogada.

A diferencia de lo que sucede en los debates escritos en verso, en los cuales dos principios opuestos argumentan a favor o en contra mediante una serie discursiva de razonamientos, en el amebeo se produce un contraste emocional o estético entre los respectivos puntos de vista de los pastores, pero no hay un intento por parte de ninguno de los dos para persuadir al otro. El pastor que canta en segundo lugar no refuta, ni tampoco acepta, la validez de las afirmaciones que ha formulado el pastor que le precede. La definición del amebeo, en consecuencia, se caracteriza desde un punto de vista pragmático por su peculiar «dicción» en cuanto el canto del pastor-poeta suspende las condiciones habituales que imperan en la situación comunicativa. De modo paralelo, en la competencia poética establecida por los pastores, el componente lúdico de la misma se desarrolla mediante la estilización de la oralidad primaria del lenguaje, así como por la reelaboración del componente folklórico asociado a los primitivos rituales de la contienda pastoril.

Si de la variante más combativa y realista del amebeo es buena muestra la égloga III de Virgilio, inspirada en el idilio V de Teócrito, donde los pastores Menalcas y Dametas intercambian insultos ya que se acusan mutuamente de ladrones de ganado y se desafían a cantar con el propósito no sólo de vencer, sino de humillar a su adversario, Garcilaso opta por imitar la variante más idealizada del amebeo incluida en la égloga VII de Virgilio, como hemos visto $^{22}$. A partir de la imitación del poeta toledano, los elementos competitivos más agresivos tales como el juez, la apuesta y el vencedor, se atenúan o casi

latino». Por su parte, Montero (2002: 183) comenta sobre las tres églogas garcilasianas: «constituyen un conjunto dotado de una madurez artística tal, que bien podemos considerarlo - en proporción inversa a su temprana aparición - el culmen del género en nuestras letras».

${ }^{22}$ En la virgiliana égloga III, Dametas apuesta una vaca y Menalcas, ya que no es dueño del rebaño que pastorea, se ve en la obligación de apostar una copa de haya. Hay también un juez de la contienda elegido por ellos: Palemón, quien dictamina el orden de la competición: «Incipe, Damoeta; tu deinde sequere, Menalca./ Alternis dicetis; amant alterna Camenae» (III, 58-59), si bien permanece indeciso sin conceder la victoria a uno u otro. No ocurre así en el idilio V de Teócrito, cuando el juez Morsón proclama como vencedor a Comatas. 
desaparecen de la trayectoria del amebeo, aun con las inevitables excepciones ${ }^{23}$. El paso a la escritura podría servir para explicarnos por qué los poetas se sienten progresivamente más interesados en las posibilidades artísticas del amebeo, antes que por el combate verbal que, aunque derivado de su contexto polémico, se muestra cada vez más alejado de la primitiva oralidad del canto propiciando su reelaboración poética, de acuerdo con la hipótesis siguiente de Walter Ong (1987: 49): «La escritura propicia abstracciones que separan el saber del lugar donde los seres humanos luchan unos contra otros. Aparta al que sabe de lo sabido. Al mantener incrustado el conocimiento en el mundo vital humano, la oralidad lo sitúa en un contexto de lucha».

Los escritores tanto del Renacimiento como del Barroco eran muy conscientes de la poética literaria del «Amebeo/alterno canto» (Soledad 2. ${ }^{\mathrm{a}}$, vv. 626-627), casi siempre incluido en un poema de mayor extensión: la égloga, mediante un narrador que lo introduce: «Las formas, apuntemos sin más tardar, suelen ser, efectivamente, parciales» (Guillén 1985: 167). Las formas que lo definen potencian su carácter artificioso, como afirma Lapesa (1985: 163): «El artificio de las correlaciones antitéticas con que responde cada estrofa a la anterior origina el placer de la dificultad vencida». Junto con el innegable componente artístico, la tensión que propicia el amebeo origina un diálogo literario que resulta inaceptable en sentido literal ${ }^{24}$.

Como procedimiento formal asociado a la égloga, el canto amebeo no adquiere independencia completa, pero posee sus propias convenciones literarias con respecto a otras modalidades de la poesía dialogada según lo hemos podido comprobar mediante el anterior análisis de los ejemplos seleccionados a partir de la década de los treinta cuando Garcilaso compone sus églogas que no se editan hasta 1543 , junto con el resto de su obra poética. Desde la garcilasiana égloga tercera, la trayectoria del amebeo se consolida a lo largo del siglo XVI, tanto en la variante menos clasicista de Montemayor que llega hasta Cervantes, como en la más estricta de Francisco de la Torre. Entre Cervantes, Lope de Vega y Góngora, continúa la evolución del amebeo en la

${ }_{23}$ Como el amebeo de Juan Sedeño (1997: 80-81) (traductor de la Arcadia de Sannazaro) introducido en la tercera de sus cuatro églogas originales, entre Bertulio y Crespino, presidido por un «juez perfecto y gran maestro» para proclamar el vencedor, aun cuando rechaza la apuesta: «La gloria basta agora al que vençiere,/ y al que perdiere basta la vergüenza». Falta por completo el marco competitivo en el otro amebeo que Sedeño introduce en la égloga IV: entre Flerino y Crespino. Podemos recordar también otras excepciones, como la égloga III de Juan de la Cueva a la que se refiere Ramón Mateo (1991: 772), cuando subraya la ausencia general del elemento competitivo explícito en el canto amebeo característico de la poesía española renacentista: «frente al puro placer de ejercitar en la competición las habilidades personales».

${ }_{24}$ Para la pragmática: «El diálogo es un proceso semánticamente progresivo [...] que se dirige hacia la unidad de sentido en la que convergen todas las intervenciones» (Bobes Naves 1992: 41). 
poética cultista de la égloga que culmina en las Soledades donde se mezcla con la modalidad piscatoria ensayada por Carrillo y Sotomayor. Para resumir, el amebeo permanece asociado casi siempre a la ficción del pastor-poeta que se proyecta desde una perspectiva idealizadora en el conjunto de la poesía áurea tomando como referencia la tradición virgiliana que, a través de Sannazaro, llega hasta las églogas de Garcilaso.

\section{FUENTES}

Acuña, Hernando de (1982). Varias poesías, ed. F. Díaz Larios. Madrid: Cátedra.

Carrillo y Sotomayor, Luis (1984). Poesías completas, ed. Angelina Costa. Madrid: Cátedra.

Carrillo y Sotomayor, Luis (1990). Obras, ed. Rosa Navarro. Madrid: Castalia.

Cascales, Francisco (1975). Tablas poéticas, en Introducción a la poética clasicista: Cascales, ed. A. García Berrio. Barcelona: Planeta.

Cervantes, Miguel de (2001). La Gitanilla, en Novelas ejemplares, ed. Jorge García López. Barcelona: Crítica.

Cervantes, Miguel de (2014). La Galatea, ed. Juan Montero, en colaboración con Francisco J. Escobar y Flavia Gherardi. Madrid: Real Academia Española.

Garcilaso de la Vega (1995). Obra poética y textos en prosa, ed. Bienvenido Morros. Barcelona: Crítica.

Góngora, Luis de (1994). Soledades, ed. Robert Jammes. Madrid: Castalia.

Góngora, Luis de (2010). Fábula de Polifemo y Galatea, ed. Jesús Ponce Cárdenas. Madrid: Cátedra.

Herrera, Fernando de (1985). Poesía castellana original completa, ed. Cristóbal Cuevas. Madrid: Cátedra.

Hurtado de Mendoza, Diego (1989). Poesía completa, ed. J. I. Díez Fernández. Barcelona: Planeta.

Montemayor, Jorge de (1996). La Diana, ed. Juan Montero. Barcelona: Crítica.

Montemayor, Jorge de (1996). Poesía completa, ed. J. B. Avalle-Arce, en colaboración con Emilio Blanco. Madrid: Biblioteca Castro.

Padilla, Pedro de (2010). Églogas pastoriles, ed. José J. Labrador y Ralph A. DiFranco. México: Frente de Afirmación Hispanista.

Sedeño, Juan (1997). Poesía originale, ed. G. Mazzocchi. Viareggio-Lucca: Mauro Baroni.

Soto de Rojas, Pedro (1991). Desengaño de amor en rimas, ed. facs. e introducción de Aurora Egido. Málaga: Real Academia Española/Caja de Ahorros de Ronda.

Torre, Francisco de la (1984). Poesía completa, ed. M. L. Cerrón Puga. Madrid: Cátedra.

Vega, Lope de (1994). Rimas, II [Segunda Parte], ed. Felipe B. Pedraza Jiménez. Madrid: Universidad de Castilla-La Mancha.

Vega, Lope de (2012). La Arcadia, ed. Antonio Sánchez Jiménez. Madrid: Cátedra.

Virgilio (2000). Bucólicas, ed. bilingüe de Vicente Cristóbal. Madrid: Cátedra.

\section{BIBLIOGRAFÍA CITADA}

Alonso, Álvaro (2002). La poesía italianista. Madrid: Edicioness del Laberinto.

Bayo, M. J. (1970). Virgilio y la pastoral española del Renacimiento, 2. ${ }^{\text {a }}$ ed. Madrid: Gredos. 
Blecua, Alberto (2006). «Virgilio en España en los siglos XVI y XVII» (1983), en X. Tubau (ed.), Signos viejos y nuevos. Estudios de historia literaria. Barcelona: Crítica, pp. 155174.

Bobes Naves, M. a del Carmen (1992). El diálogo. Estudio pragmático, lingüístico y literario. Madrid: Gredos.

Cristóbal, Vicente (1980). Virgilio y la temática bucólica en la tradición clásica. Madrid: Universidad Complutense.

Egido, Aurora (1985). «Sin poética hay poetas. Sobre la teoría de la égloga en el Siglo de Oro», Criticón. 30, pp. 43-77.

Escudero Martínez, Carmen (1982). «El canto amebeo en la literatura española», en Simposio Virgiliano. Murcia: s.i., pp. 3-12.

Estévez Molinero, Ángel (2002). «Los ciclos eglógicos de Eugenio de Salazar, Pedro de Padilla y Francisco de la Torre», en B. López Bueno (ed.), La égloga. Sevilla: Grupo PASO/Universidad de Sevilla, pp. 295-324.

Finello, Dominick (2014). Ámbitos y espacios pastoriles en obras y autores áureos. Madrid: Universidad de Navarra/Iberoamericana-Vervuert.

Fosalba, Eugenia (2004). «Teoría y praxis de la égloga en el siglo XVI», en M. ${ }^{a}$ José Vega y Cesc Esteve (eds.), Idea de la lírica en el Renacimiento (Entre Italia y España). Vilagarcía de Arousa: Mirabel, pp. 261-296.

Gallego Morell, Antonio (ed.) (1972). Garcilaso de la Vega y sus comentaristas. Madrid: Gredos.

García López, Jorge, Eugenia Fosalba y Gonzalo Pontón (2013). Historia de la literatura española, 2. La conquista del clasicismo, 1500-1598. Barcelona: Crítica.

Genette, Gérard (2004). Fiction et diction. Paris. Éditions du Seuil.

Gómez, Jesús (1991-1992). «Sobre la teoría de la bucólica en el Siglo de Oro: hacia las églogas de Garcilaso», Dicenda. 10, pp. 111-125.

Gómez, Jesús (1993). «El desarrollo de la bucólica a partir de Garcilaso y la poesía pastoril (siglo XVI)», Dicenda. 11, pp. 171-195.

González Vázquez, José (1991). «Influencia de Virgilio durante el Prerrenacimiento»; «Influencia de Virgilio en los escritores del primer Renacimiento», en José A. Sánchez Marín y M. López Muñoz (eds.), Humanismo renacentista y mundo clásico. Madrid: Eds. Clásicas, pp 131-154 y 155-174.

Guillén, Claudio (1985). Entre lo uno y lo diverso. Introducción a la literatura comparada. Barcelona: Crítica.

Jammes, Robert (1987). La obra poética de Don Luis de Góngora y Argote. Madrid: Castalia.

Lapesa, Rafael (1985). Garcilaso: estudios completos. Madrid: Istmo.

Lara Garrido, José (1994). La poesía manierista de Luis Barahona de Soto (lírica y épica del manierismo). Málaga: Diputación Provincial de Málaga.

López Bueno, Begoña (ed.) (2002). La égloga. Sevilla: Grupo PASO/Universidad de Sevilla.

López Bueno, Begoña (2005). «Sobre el estatuto teórico de la poesía lírica en el Siglo de Oro», en B. López Bueno (ed.), En torno al canon: aproximaciones y estrategias. Sevi1la: Grupo PASO/Universidad de Sevilla, pp. 69-96.

Marín Cepeda, Patricia (2015). Cervantes y la corte de Felipe II. Escritores en el entorno de Ascanio Colonna (1560-1608). Madrid: Eds. Polifemo.

Mateo Mateo, Ramón (1991). La poesía pastoril española del siglo XVI. Madrid: UNED

Montero, Juan (1996). «Sobre las relaciones entre la elegía y la égloga en la poesía del Siglo de Oro», en B. López Bueno (ed.), La elegía. Sevilla: Grupo PASO/Universidad de Sevilla/Universidad de Córdoba, pp. 215-226. 
Montero, Juan (2002). «Las églogas en la poesía española del siglo XVI: panorama de un género (desde 1543)», en B. López Bueno (ed.), La égloga. Sevilla: Grupo PASO/Universidad de Sevilla, pp. 183-206.

Novo, Yolanda (1996). «La elegía en el primer tercio del siglo XVII: en torno a Lope de Vega», en B. López Bueno (ed.), La elegía. Sevilla: Grupo PASO/Universidad de Sevilla/Universidad de Córdoba, pp. 227-260.

Novo, Yolanda (1998). "“Canté versos bucólicos/ con pastoril zampoña, melancólicos". Formas y géneros del bucolismo lopiano en torno a Rimas», Anuario Lope de Vega. IV: 253-283.

Núñez Rivera, Valentín y J.M. Rico García (2005). «Sobre poesía del Siglo de Oro. Un estado de la cuestión (1999-2002)», Etiópicas. Revista de las Letras Renacentistas. 1, pp. 72-129.

Ong, Walter (1987) [1982]. Oralidad y escritura. Tecnologías de la palabra, trad. esp. México, FCE.

Osuna Rodríguez, Inmaculada y Antonio Sánchez Jiménez (2012). «Tendencias en los estudios de poesía del Siglo de Oro (2008-2011)». Etiópicas. Revista de las Letras Renacentistas. 8, pp. 237-678.

Pedraza Jiménez, Felipe B. (2003). El universo poético de Lope de Vega. Madrid: Eds. del Laberinto.

Pérez-Abadín, Soledad (2004). "Resonare siluas". La tradición bucólica en la poesía del siglo XVI. Santiago de Compostela: Universidade.

Pérez-Abadín, Soledad (2009). «La Bucólica del Tajo de Francisco de la Torre como poema pastoril: visión de conjunto», Criticón. 105: 85-116.

Pérez-Abadín, Soledad (2012). La configuración de un libro bucólico. Églogas pastoriles de Pedro de Padilla. México: Frente de Afirmación Hispanista.

Ponce Cárdenas, Jesús (2001). Góngora y la poesía culta del siglo XVII. Madrid: Eds. del Laberinto.

Prieto, Antonio (1984 y 1987). La poesía española del siglo XVI. Madrid: Cátedra, 2 vols.

Rozas, Juan Manuel (1990). "Lope de Vega y Felipe IV en el "ciclo de senectute"», en J. Cañas Murillo (ed.), Estudios sobre Lope de Vega. Madrid: Cátedra, pp. 73-133,

Ruestes, M. ${ }^{a}$ Teresa (1989). Las églogas de Fernando de Herrera. Barcelona: PPU.

Ruiz Pérez, Pedro (2002). «Égloga, silva, soledad», en B. López Bueno (ed.), La égloga. Sevilla: Grupo PASO/Universidad de Sevilla, pp. 387-429.

Schnabel, Doris (1996). El pastor poeta. Fernando de Herrera y la tradición pastoril en el primer Siglo áureo. Kassel: Ed. Reichenberger.

Toro Valenzuela, Bernardo (2002). «El género de la égloga en el Desengaño de amor en rimas de Soto de Rojas», en B. López Bueno (ed.), La égloga. Sevilla: Grupo PASO/ Universidad de Sevilla, pp. 325-339.

Vega, M. ${ }^{a}$ José y Cesc Esteve (eds.) (2004). Idea de la lírica en el Renacimiento (Entre Italia y España). Vilagarcía de Arousa: Mirabel.

Ynduráin, Domingo (2000). Del clasicismo al 98. Madrid: Biblioteca Nueva.

Fecha de recepción: 4 de noviembre de 2015.

Fecha de aceptación: 25 de noviembre de 2016. 